University of Pennsylvania Carey Law School

Penn Law: Legal Scholarship Repository

Faculty Scholarship at Penn Law

9-7-2015

\title{
Can Simple Mechanism Design Results be Used to Implement the Proportionality Standard in Discovery?
}

Jonah B. Gelbach

University of Pennsylvania Carey Law School

Follow this and additional works at: https://scholarship.law.upenn.edu/faculty_scholarship

Part of the Civil Procedure Commons, Courts Commons, Economic Theory Commons, Law and Economics Commons, Litigation Commons, Policy Design, Analysis, and Evaluation Commons, Political Economy Commons, Public Economics Commons, and the Public Policy Commons

\section{Repository Citation}

Gelbach, Jonah B., "Can Simple Mechanism Design Results be Used to Implement the Proportionality Standard in Discovery?" (2015). Faculty Scholarship at Penn Law. 1617.

https://scholarship.law.upenn.edu/faculty_scholarship/1617

This Article is brought to you for free and open access by Penn Law: Legal Scholarship Repository. It has been accepted for inclusion in Faculty Scholarship at Penn Law by an authorized administrator of Penn Law: Legal Scholarship Repository. For more information, please contact PennlawIR@law.upenn.edu. 


\title{
Can Simple Mechanism Design Results be Used to Implement the Proportionality Standard in Discovery?
}

\author{
by \\ Jonah B. Gelbach*
}

September 7, 2015

\section{Introduction}

The American federal civil litigation system is distinctive in numerous ways. One that has been the focus of ongoing controversy is the extensive system of litigant-initiated discovery in the U.S., which operates under the strong presumption that the party responding to a discovery request bears the direct costs of compliance with that request. This system gives parties to a civil lawsuit the ability to impose potentially substantial information-gathering costs on their adversaries. While the empirical facts are disputed, it is often argued that this cost-externalization ability leads to misuse of the discovery process.

For several decades, proponents of reform have pushed for changes to Federal Rule of Civil Procedure 26, which sets forth the overall framework of civil discovery in the U.S. system. The history and details of efforts to restrict or modify the terms of discovery are too complex for discussion here. ${ }^{1}$ However, a pending rule change, which will take effect December 1, 2015, unless Congress acts to stop it, has rewritten and re-emphasized the text of what has come to be known as the discovery proportionality standard. ${ }^{2}$ Here is a summary, if certainly a serious over-simplification, of the proportionality standard, mapped into simple economic terms: in at least some cases where only monetary damages are at stake, discovery will be considered non-proportional if the plaintiff's perceived benefits are less than the costs to the defendant of providing it. For example, a request to

\footnotetext{
${ }^{*}$ University of Pennsylvania Law School. I thank Urs Schweizer and Holger Spamann for thought-provoking comments. In addition, I thank Christoph Engel, Eric Helland, Jennifer Reinganum, and all the other participants at the 2015 JITE "Beyond Privity" conference, for helpful suggestions and comments.

${ }^{1}$ For discussions with some details, see, e.g., Gelbach and Kobayashi (forthcoming) or Gelbach (2015).

${ }^{2}$ The Proposed Rules submitted for Congressional consideration by Chief Justice John Roberts, together with substantial commentary from various players in the Rulemaking process, are available at http://www.uscourts.gov/file/18022/download?token $\overline{4}$ S6SRw0T.
} 
conduct discovery that would cost $\$ 200,000$ would in many cases fail the proportionality standard if the plaintiff seeks only $\$ 100,000$ in damages. ${ }^{3}$

While the text of the new Rule is not obviously that different from earlier versions, many worry - and others hope - that federal trial courts will respond by tightening up on requesters' access to discovery. If proportionality objections to discovery become more common, federal judges will have to use a subjective balancing approach, based on several difficult to observe factors, to determine whether to allow discovery. The direct costs of conducting discovery may be difficult for judges to observe. So too with the subjective ex ante values the parties place on having the fruits of future discovery: presumably plaintiffs and defendants sometimes agree and sometimes disagree concerning these values.

The challenges of eliciting information under such conditions are of course not new to economists; they are the domain of mechanism design. One aim of this paper, therefore, is to ask whether mechanism design can help judges create incentives that would induce partes to provide the relevant information.

An antecedent question, though, is why discovery occurs at all. Discovery is costly and unlikely to be valuable to the producing party outside litigation. From an ex ante perspective, then, there is the possibility that agreeing to forego discovery would create some surplus. Therefore, parties with sufficiently aligned beliefs about the likely results of producing discovery might often have an incentive to engage in what I call a "discovery settlement": an agreement in which one party pays the other to forego discovery, even if the overall lawsuit is not settled. The possibility that such efficient trades might occur echoes the Coase Theorem: with no bargaining costs, agents will reach efficient bargains in the absence of outside intervention, and regardless of the particular rules of discovery.

I emphasize that even when Coasean results do obtain, the discovery cost allocation rule will affect the distribution of welfare, as usual in Coasean analysis. Obviously, requesters will do better under a system in which they must be paid to forego discovery demands than under a system in which they must pay responders to carry them out. It is widely thought that liberal discovery imposes greater burdens on defendants than on plaintiffs, which helps to explain the why organizations that represent the interests of those who are more frequently defendants in consumer/employee-versus-business litigation have supported increasing the emphasis on proportionality, as well as, in some cases, a shift to responder-can-refuse. It also helps to explain why plaintiff-side attorneys, public interest organizations, and academics who are often sympathetic to plaintiffs' interests have generally opposed this increased emphasis.

\footnotetext{
${ }^{3}$ The primary exception to this generalization involves situations in which conducting the discovery likely would create valuable spillovers. For example, suppose 100 plaintiffs have sued the same defendant in 100 different cases, with each plaintiff seeking $\$ 100,000$ in damages for the same alleged misconduct. Suppose the proper disposition of all 100 cases would be substantially more likely via discovery that costs the defendant $\$ 1$ million. The language of the proportionality standard creates space for the judge in one of the 100 cases to find the discovery in question proportional. Discovery might also be found proportional if it were valuable to future regulatory or policy making work, and so on.
} 
To my knowledge, the simple Coasean point that disfavored discovery will not happen if bargaining is sufficiently easy, has not been made either in debates among litigation policy makers or among scholars. That should be surprising, since Coasean ideas have been around for half a century, ${ }^{4}$ only slightly longer than economic analyses of the civil litigation system, ${ }^{5}$ while concerns about the overuse of discovery are also not new. ${ }^{6}$ To be sure, there has been a lot of analysis concerning the question of whether the American rule or the British rule is better, and whether this question is even sensible in light of Coasean reasoning. ${ }^{7}$ And there have been numerous analyses focused at least in part on the role of discovery in civil litigation. ${ }^{8}$ But none of these analyses seriously considers the possibility that the parties might bargain discretely over the right to discovery, "settling" only that question while continuing to keep the overall litigation alive. Indeed, Cooter and Rubinfeld's (1994, p. 454) influential paper on the issue of discovery specifically assumes "that the plaintiff and defendant cannot cooperate together and reach a mutual agreement to constrain discovery." Yet it seems likely, and if not certain, that discovery settlements would be enforceable via joint stipulation. After all, stipulations happen all the time in federal civil litigation, including those involving agreements limiting or describing the extent of discovery that will be conducted. ${ }^{9}$ In this paper I conduct the Coasean thought experiment of asking whether, when bargaining is frictionless, efficient deals to avoid disfavored discovery would obtain.

To frame the discussion of legal rules and the efficiency of dicovery, I imagine that the federal courts adopted a supercharged version of the proportionality standard, by simply shifting to a system in which the responder has the right to refuse discovery requests for any reason. Under this alternative "responder-can-refuse" rule, requesters would have to compensate responders not only for the direct costs of providing discovery, but also for the responder's ex ante valuation of the costs to the responder due to a shift toward the requester in the case's merits. ${ }^{10}$

\footnotetext{
${ }^{4}$ See Coase (1960).

${ }^{5}$ See, e.g., Posner (1971).

${ }^{6}$ See, e.g., Easterbrook, "Discovery as Abuse" (1989); Mullenix (1994).

${ }^{7}$ See, e.g., Shavell (1982) and Donohue (1991).

${ }^{8}$ See, e.g., Cooter and Rubinfeld (1994); Hay (1994); Sobel (1989); Shavell (1997); Shavell (1989); Mnookin and Wilson (1998); Farmer and Pecorino (2013).

${ }^{9}$ Indeed, Rule 26(f) requires the parties to attempt to agree on a discovery plan, and other Rules implicitly or explicitly provide for stipulations waiving discovery rights.

${ }^{10} \mathrm{~A}$ number of commentators have proposed shifting to an intermediate rule under which the requester must pay for discovery; see CITES [including Cooter and Rubinfeld's two-part rule]. Rule 26(c) currently provides that parties facing discovery requests may seek an order "to protect a party or person from ... undue burden or expense," including the imposition of various terms on the discovery in question. Another proposed amendment to Rule 26 would add "the allocation of expenses" to the list of such terms. That would explicitly allow judges to require the requester to pay some or all of the cost of providing the requested discovery. Note that this legal rule would introduce a further adjudicative difficulty - determining which expenses are reasonable and thus shiftable to the requester. An assessment of that rule would require one to take seriously the possibility of private information concerning the direct cost
} 
I verify the expected Coasean result in a stylized model, which I introduce in section 2. In the model, a plaintiff-requester and a defendant-responder each receive a signal indicating the likely value to the plaintiff's case of discovery-low or high. I show that when parties' ex ante expectations concerning the value of discovery are known to each other, Coasean bargains ensure that discovery occurs if and only if it is ex ante subjectively efficient.

In reality, of course, agents' subjective beliefs are private information. Given specified terms of Coasean bargains, parties might have incentives to either overstate or understate their subjective beliefs concerning the value of discovery. With private information about valuations, then, bargaining costs generally will not be zero. Consequently, the standard Coasean analysis does not apply, and the Coasean result concerning the efficiency of observed discovery might not hold. In section 3, I address this issue by using results from the mechanism design and auction theory literatures to show how it would be possible, for a court that knew the distribution of parties' beliefs and valuations, to construct a mechanism that would induce truthful revelation of the parties' realized valuations. This mechanism would allow the court to avoid not just disfavored discovery, but also any use of discovery when the requester's subjective valuation of discovery is less than the responder's overall subjective cost. That is, the mechanism achieves ex post efficient results at the discovery stage. It also gives each party at least the payoff it would receive if the party refused to participate in any the mechanism and trade were impossible (a property known as interim individual rationality). Further, the range of payoff distributions the court can achieve includes as a special case the distribution that would obtain if the parties could engage in costless Coasean bargaining with a fixed share of surplus going to the plaintiff. Finally, while the mechanism does not break even in every state of nature, on average it requires no outside subsidies.

What makes the mechanism work, aside from the conventional if troubling assumption that its designer knows all relevant parameters, is the dependence in the joint distribution of parties' valuations of discovery: when one party thinks discovery is likely to be highly valuable, so does the other. Under such conditions, Cremer and McLean (1988) have shown that it is possible to design a mechanism that satisfies all the conditions in the previous paragraph. ${ }^{11}$ The mechanism I construct is based on their ideas, and very similar to one displayed in McAfee and Reny (1992).

The efficient mechanism results come from an admittedly very stylized model. But they suggest that a court with enough information to fully implement the proportionality

\footnotetext{
of discovery provision.

${ }^{11}$ Myerson and Satterthwaite (1983) have famously showed that the collection of properties described in the text cannot all occur in bilateral trade with continuously and independently distributed private valuations whose supports overlap. Schweizer (1989) presents a two-sided asymmetric litigation model, with parties having common values in terms of their types, but with (i) party types distributed independently and (ii) party type distributions each having two points of support. Schweizer finds a similar result to Myerson and Satterthwaite's: the properties described in the text are not all achievable if there is nontrivial overlap in a certain notion of the parties' expected payoffs. The Cremer and McLean (1988) result does not hold in these papers because in these papers agents' valuations are assumed independent.
} 
standard described above could do quite a bit more: it could avoid disfavored discovery while avoiding any redistribution of payoffs across parties due to restrictions on discovery. That is important because distributional considerations have played an important role in arguments over discovery reform in the U.S.

If that is the glass-is-half-full interpretation, there is also a half-empty one. The informational requirements for the court to implement the mechanism just described are enormous. It seems unlikely that courts will be able to do so in practice - just as it seems unlikely they will be able to easily implement a system that effects the proportionality standard in the proposed-amended Rule 26.

What can or should a court do if it cannot design such mechanisms? That is the subject of section 4. One approach would be for the court to auction off the discovery right. Another would be to use a "posted-price" mechanism: the court announces a price, and the right trades if and only if both parties agree to do so at the posted price. ${ }^{12}$ As I discuss below, relevant forms of truth-telling are at least a weakly dominant strategy with both mechanisms in the model I consider. But auctioning off the discovery right has significant distributional consequences. And it is not clear how the court would know what price to post, which is problematic since a poor choice could lead to the conduct of disfavored discovery, or the failure of approved discovery to occur. A third alternative that I address in only general terms would be for the court to adopt the Chatterjee and Samuelson (1983) split-the-difference mechanism. That mechanism creates incentives to behave strategically, ${ }^{13}$ and there is no reason to think it will be ex post efficient (even when correlated types would allow a sufficiently informed mechanism designer to achieve ex post efficiency). In sum, all of the administratively feasible mechanisms considered have some normatively important drawback.

In section 5, I discuss the extent to which pre-discovery settlement of the overall case - something that assuredly does happen in many cases - might replicate the performance of discovery settlements. Finally, I conclude in section 6.

Before I turn to the model, I address the important background question of what the court's objective should be. The conventional answer for economists would be something like social welfare, after accounting for all effects of discovery rulings. These effects would include not only the direct costs of discovery and the parties' expectations concerning its fruits, but also any encouragement or deterrence of behavior outside the lawsuit in question. $^{14}$

I shall not undertake that sort of conventional analysis, however. For one thing, the proportionality standard does not exist in a procedural vacuum. Rule 1, for example, states that the Federal Rules of Civil Procedure "should be construed and administered

\footnotetext{
${ }^{12}$ Posted prices are an example of robust mechanisms. On robust mechanism design, see Dirk Bergemann and Stephen Morris, "Robust Mechanism Design", 73 Econometrica 1771-1813 (2005) and Takuro Yamashita, "Implementation in Weakly Undominated Strategies: Optimality of Second-Price Auction and Posted-Price Mechanism", forthcoming in Review of Economic Studies (2015).

${ }^{13}$ See, e.g., Myerson and Satterthwaite (1983); see also Lee and Klerman (2014).

${ }^{14}$ See, e.g., Kaplow (1994), for a discussion of such effects.
} 
to secure the just, speedy, and inexpensive determination of every action and proceeding." Depending on how one implements the proportionality standard, the weights placed on justice, speed, and frugality might well be altered. ${ }^{15}$ Further, there are numerous statutes in which Congress has provided for one-way fee shifting, with the result that defendants are responsible for the litigation expenses incurred by victorious plaintiffs. ${ }^{16}$ These statutes are widely viewed as representing a legislative determination in favor of private, rather than simply public, enforcement of certain rights, typically of ones with discernible demographic groups as plaintiffs. These statutes were also enacted against the backdrop of existing Federal Rules. ${ }^{17}$ More generally, amendments to the Federal Rules are not supposed to "abridge, enlarge or modify any substantive right,"18 so it would be inappropriate to use Rules changes to alter the social objective function, at least for suits in such spheres, in light of new emphasis on proportionality in discovery. Further, if a beefed-up proportionality standard led to a reduction in settlements, it would conflict with the "public policy favoring the compromise and settlement of disputes" flagged by the Advisory Committee on Rules of Evidence in explaining why Federal Rule of Evidence 408 generally prohibits admissibility at trial of settlement offers; see also Marek v. Chesny, 473 U.S. 1, 10 (1985), which explains that Rule 68's offer of judgment terms expresses a "clear policy of favoring settlement of all lawsuits." In sum, it is difficult to discern an "overall" bottom line for analyzing how a new emphasis on proportionality could be expected to affect the performance of the civil litigation system as a whole.

In this paper, therefore, I shall not attempt a system-level evaluation of the effects of greater emphasis on the costs and benefits of discovery. My more modest approach instead begins with the idea that U.S. federal courts can be expected (i) to approve of conducting discovery when the parties have a good-faith ex ante disagreement over

\footnotetext{
${ }^{15}$ For example, some believe that a responder-pays discovery system generates many unjust impositions of expense, time, and hassle; see, e.g., Redish (2012). Others believe that discovery is absolutely necessary to hold wrong-doers to account, especially those with the resources to keep evidence from coming to light through alternative means. Depending on the substantive law, it is easy to imagine that a proportionality standard with teeth would alter the balance between these two justice interests. Further, justice, speed and inexpense are objectives that often must be traded off rather than being simultaneously achieved in maximal measure. If the proportionality standard induces more procedural wrangling, it might slow down pre-trial proceedings substantially, even if its end result is socially desirable according to one's chosen metric. It might also require greater judicial expense even if it reduces the would-be responder's expense.

${ }^{16}$ Examples in which such one-way fee shifting statutes exist include many types of civil rights and employment-related lawsuits. Examples with two-way fee shifting-functionally, the British rule - are much less common; copyright is one such setting. See 17 U.S.C. 505; see also 35 U.S.C. 285 , which provides for the award of fees to the prevailing party in "exceptional cases."

${ }^{17}$ See Burbank (2015) (noting that "The Supreme Court is fond of reminding us that Congress legislates against the background of the Federal Rules").

${ }^{18}$ See 28 U.S.C. 2072(b).
} 
the expected value of discovery in the case, with the requester sincerely believing the requested discovery's value exceeds the cost of providing it, and (ii) to generally disapprove of conducting discovery otherwise. ${ }^{19}$ The text of the proposed-amended Rule 26(b)(1) suggests that this approach at least in large measure captures the concerns motivating discovery-rule reformers; general commentary from those favoring the amendment is also in line with it.

\section{The Model and Complete Information Results}

There are two parties: a single plaintiff, $\mathrm{P}$, and a single defendant, D. If the case goes to trial, a jury will determine whether the defendant is liable to the plaintiff, based on the evidence that the parties present. If the jury finds the defendant liable, the defendant will have to pay 1 unit of damages to the plaintiff; otherwise no damages will be paid by either party.

\subsection{Types of Evidence in the Model}

There are two types of evidence relevant to the dispute. The first type of evidence includes testimony of the parties or other witnesses who have freely given publicly available statements. Each party has access to such "common knowledge evidence". ${ }^{20}$ Because they have different assessments of the favorability of the jury pool, the quality of the common knowledge evidence, the favorability of the legal standard, or any combination of these, the parties disagree about what will happen at trial if only common knowledge evidence is presented: the plaintiff believes that she will win with probability $q$, while the defendant believes that the plaintiff will certainly lose. The parties' beliefs about this probability are common knowledge. The plaintiff believes the defendant is optimistic, and the defendant believes the plaintiff is. Both understand that at most one can be right, but there they are. ${ }^{21}$

\footnotetext{
${ }^{19}$ An important caveat is that discovery sometimes has external social effects - benefits that accrue to, or costs that are inflicted on, non-parties. For analytical contributions on this issue, see Shavell (1997) and Hay (1994); for discussions in the context of the propsed amendments to the discovery proportionality standard, see Gelbach and Kobayashi (forthcoming) and Burbank (2015).

${ }^{20}$ Other examples of common knowledge evidence would include public documents or recordings, easily photographed scenes, and so on.

${ }^{21}$ Such "mutual optimism" or "divergent expectations" models, which involve inconsistent priors, have to a large extent fallen out of favor in economic modeling of litigation. For criticisms, see, e.g., Wickelgren (2013) or Daughety and Reinganum (2012); see also (Daughety and Reinganum, 2014, p. 84), who describe signalling and screening asymmetric information models as "the two workhorses of settlement bargaining analyses." While asymmetric information models are interesting and may provide some insights, they also typically place a lot of artificial structure on litigation behavior (on this point, see Daughety and Reinganum (1993)), and there is no good empirical reason of which I am aware to assume that people having disputes have consistent priors about what will happen at trial. The emphasis on asymmetric information
} 
Each party's trial cost, measured in units of damages, is $\tau \in(0,1)$, and the American rule holds, so that each party bears its own litigation costs. I assume all of the foregoing information is common knowledge. Therefore, if there is only common knowledge evidence, the case will go to trial if and only if there is not positive surplus to be had from settlement. In the event of trial, the defendant's subjective cost is $\tau$, while the plaintiff's subjective gain is $q-\tau$. Therefore, the surplus from settling is $2 \tau-q$. To simplify the discussion, I focus on cases that would go to trial in this situation, so I shall assume that $q>2 \tau$.

The second type of evidence is evidence that a party must physically possess, and which is in the possession of exactly one party (though copies can be made). For simplicity, I assume that only the defendant holds any such "privately held evidence". The defendant's cost of providing privately held evidence - whether for its own use or to the other party via discovery - is $c$. Because the discovery of privately held evidence is costly, it is possible that the parties will be able to reach a bargain that avoids costly discovery. I call such a bargain a "discovery settlement" in order to emphasize that only the question of whether costly discovery is provided is necessarily determined in such a partial settlement; the overall case would continue.

As an example of privately held evidence, consider the contents of email traffic among a firm's employees. The cost of providing such evidence includes searching the firm's backed-up email for relevant information, as well as expenses related to redaction and privilege-logging. It seems natural to imagine that the contents of privately held evidence might be asymmetrically known, even before expenditures are made to provide it in discovery. For example, even without having searched its warehoused email, the defendant might know for sure that it contains damaging information; the plaintiff might suspect only the possibility that such damaging information exists. However, it is also possible that the defendant does not know how damaging the email contents are and cannot know without paying most or all of the costs of providing the evidence in the first place. And it is also possible that the plaintiff knows for sure, or at least with high probability, that the contents are damaging-say, because the plaintiff herself has seen such email, or because of anonymous tips from one of the defendant's employees. Thus I assume that each party receives a (free) signal from nature about the value of the defendant's privately held evidence.

Let $s_{i} \in\{0,1\}$ be $i$ 's signal about the value of the defendant's privately held evidence,

to the total exclusion of inconsistent priors seems to be largely the result of methodological trends in economic theory, rather than an empirically grounded development. (Schweizer, 1989, p. 164), who provides an interesting and thoughtful asymmetric information model, put it well when he wrote: "Obviously, decisions based on unqualified judgement and faulty views can lead to litigation and, in fact, may actually do so quite frequently in real life. But, given that the rationality of man is stressed elsewhere, the approach does not appear to be in accord with the usual reasoning in the economic analysis of law. To preserve the postulate of rationality, deviating assessments should rather be attributed to parties holding private information on the merit of the case." (Emphasis added.) Recent papers that at least partially adopt the divergent expectations approach include (Rosenberg and Spier, forthcoming, Part III.4) and Lee and Klerman (2014). 
and define $\delta_{i} \equiv \alpha s_{i}+\lambda\left(1-s_{i}\right)$. Leaving aside the effects of party $j$ 's signal for the moment, the parameter $\alpha$ is the increase in the value at trial of the plaintiff's case that $i$ would expect when the signal value is 1 , while $\lambda$ is the increase in this value when the signal is $0 .{ }^{22} \mathrm{I}$ assume $\alpha>\lambda$, so $s_{i}=1$ is a high-value signal and $s_{i}=0$ is a low-value signal.

Now consider the interaction of parties' signals. At the time they are received, if party $i$ knew both its signal and party $j$ 's, it would believe that the use of privately held evidence would increase the plaintiff's payoff at trial by $\delta_{i}+\gamma \delta_{j}$, where $\gamma \geq 0$. Thus, $\gamma$ measures the sensitivity of each party's discovery-related payoff to the other party's discovery-related information. For example, if both parties received the signal that discovery is highly valuable -i.e., $s_{d}=s_{p}=1$ - then just before discovery occurred, the plaintiff's subjective value of her case would be $q-\tau+\alpha(1+\gamma)$, while the defendant's subjective cost would be $-\tau-\alpha(1+\gamma)$.

The parameter $\gamma$ allows for the possibility that the parties are differentially confident in each other's signals. If we were to insist on common priors concerning discovery's value to the plaintiff, then we would have $\gamma=1$. Under this assumption, discovery would always be privately wasteful if the parties had complete information about each other's pre-discovery signals. Since discovery is costly to conduct, the parties would always agree not to conduct discovery, and even without complete information, it is difficult to see how discovery would not inevitably be socially wasteful in the absence of spillovers outside the case. I do not believe such a state of affairs would be accepted as an accurate description of reality by most lawyers, judges, or legal policymakers. In reality, parties or their attorneys might be overconfident about their own capacity to read their signals, or they might doubt the capacity of their opponents to accurately read their signals, even while ascribing good faith to them. There is no shortage of evidence that people engage in self-serving beliefs, and litigation is a very ripe locus for motivated reasoning. ${ }^{23}$ Thus, I shall assume that $\gamma<1$, so that parties put more weight on their own signals than on their adversaries'. This means that it would sometimes be subjectively Pareto

\footnotetext{
${ }^{22}$ We might think of $\lambda$ and $\alpha$ as representing an increase in the plaintiff's probability of winning the case and receiving 1 unit of damages. In that case logic requires that $\alpha<1-q$. But we could also think of these parameters as representing both an increase in the plaintiff's probability of winning and an increase in the damages she receives when she wins, with all other variables still measured in units of damages based on only common knowledge evidence, so I shall not worry about any upper bound on these discovery-value parameters.

${ }^{23}$ As suggested in footnote 21 above, I do recognize that many, if not most, builders of economic models would reject the possibility of such beliefs, on the theory that fully rational agents with the same information should hold the same beliefs about the implications of that information. I might cheekily point out that anyone who disagrees with me on this point must either be wrong or have conceded that I am wrong. And since I'm not going to be disabused of my view, the only equilibrium is one in which at least someone either is irrational, is wrong, or is going to disagree despite being rational. On the question of whether everyone in the world is rational, see generally discussions of Lawrence Summers's famous but difficult-to-find paper, which began with the following two sentences: "THERE ARE IDIOTS. Look around." (See blog post by Ezra Klein, "There are idiots. Look around.", http:voices.washingtonpost.comezraklein-200910there_are_idiots_look_around.html, October 23, 2009.)
} 
optimal for discovery to occur, even under complete information. For simplicity given the illustrative nature of this paper's model, I shall go even further, and assume that $\gamma=0$. This simplifies aspects of the analysis by yielding a private-value problem, though my preliminary analysis suggests that all the important qualitative results likely hold, or can be sensibly modified, without this assumption. In addition to the assumptions above, I shall assume throughout that $0<\lambda<c<\lambda+c<\alpha$.

\subsection{Coasean Results with Complete Information over Signal Values}

In the first case, assume that the parties receive the same signals about the value of privately held evidence, so that $\delta_{p}=\delta_{d}=\delta$. Since it is costly to discover the evidence, there is positive surplus available from a discovery settlement. The defendant's total cost from undergoing discovery is $c+\delta$, while the plaintiff's total gain is $\delta$, so the amount of surplus available is the cost of discovery, $c$. Let the plaintiff's share of surplus in bargaining be $\beta$. Then in equilibrium, the defendant will pay the plaintiff her reservation value plus the share $\beta$ of the discovery cost, i.e., $\delta+\beta c$. There will be no discovery, and the case will go to trial with only common knowledge evidence introduced. ${ }^{24}$ Expected payoffs as of the pre-discovery stage will be $(\delta+\beta c)$ for the plaintiff and $-(\delta+\beta c)$ for the defendant.

Next, suppose that $s_{p}=0$ and $s_{d}=1$. In this situation the parties will also reach a discovery settlement. The defendant's subjective total cost of conducting discovery is $\alpha+c$, which exceeds the plaintiff's subjective gain of $\lambda$. In equilibrium, the defendant will pay the plaintiff $\beta(\alpha+c-\lambda)$; once again there will be no discovery, and the case will go to trial with only common knowledge evidence introduced. Discovery stage payoffs will be $\beta(\alpha+c-\lambda)$ for the plaintiff and $-\beta(\alpha+c-\lambda)$ for the defendant.

Finally, suppose $s_{p}=1$ and $s_{d}=0$, so that the defendant's subjective total cost of discovery $c+\lambda$, while the plaintiff values it at $\alpha$. In this case, the parties' disagreement about the value of the defendant's privately held evidence means that discovery settlement will not be feasible. Since $\alpha>c+\lambda$ by assumption, the plaintiff's subjective belief is that discovery is more valuable than the defendant's overall subjective cost of providing it. There will be no discovery settlement, so costly discovery will occur. The plaintiff's payoff is $\alpha$, while the defendant's is $-(c+\lambda)$.

Now consider what happens if we switch from a responder pays discovery system to one in which the requester must purchase the right to discovery from the responder. We have the usual Coasean result: given that the parties can bargain costlessly, discovery will occur if and only if its subjective value to the plaintiff is greater than its subjective cost to the defendant. In particular, whether discovery occurs does not depend on the allocation of discovery rights.

Of course, the distribution of payoffs very much depends on the allocation of the right to demand or refuse discovery. If we reverse the discovery cost allocation rule, then the defendant will not have to pay the plaintiff to avoid discovery in those instances in which

\footnotetext{
${ }^{24}$ Recall that the parties' disagreement concerning the common knowledge evidence is sufficient to render pre-trial settlement in the absence of discovery impossible.
} 
it does not occur. Thus, both parties' discovery stage payoffs will equal 0 in any state in which discovery does not occur. In the one state in which discovery does occur-when $s_{p}=1$ and $s_{d}=0$ - the surplus from trade is $(\alpha-c-\lambda)$ and the parties' reservation payoffs are 0 , so the defendant's payoff will be $(1-\beta)(\alpha-c-\lambda)$, while the plaintiff's will be $\beta(\alpha-c-\lambda)$. Switching the discovery cost allocation rule thus strictly reduces the plaintiff's payoffs, while strictly increasing the defendant's.

As usual in the zero-bargaining costs setting, then, the endowment of rights has important normative implications (unless wealth maximization is the social objective function). At the level of generality considered in the model that assumes ex post efficient bargains always occur, then, the choice between discovery cost allocation rules has nothing to do with how much discovery occurs, and boils down to a purely distributional choice.

An obvious question is how the parties can be expected to find their way to a discovery settlement when their mutual signals are private information, rather than common knowledge. ${ }^{25}$ I turn to that issue in the next sections.

\section{A Mechanism Implementing the Ex Post Efficient Result}

In this section I assume the court knows the probability distribution of the parties' signals, as well as the values of $c, \lambda$, and $\alpha$. I then construct a class of mechanisms based on one displayed in McAfee and Reny (1992). ${ }^{26}$ Each member of this class implements the ex post efficient result, with discovery actually occurring if and only if its value to the requester-plaintiff exceeds its overall cost to the responder-defendant. Each such mechanism also breaks even on average. Finally, the mechanisms are interim individually rational: they all provide the parties with at least their expected payoff in the no-trade regime, even after parties observe their own signals, so that no party would have to be ordered to participate. ${ }^{27}$

Define the probability that the parties' signals equal $\left(s_{p}, s_{d}\right)$ as $\pi_{s_{p} s_{d}}$. For simplicity, I shall assume that $\pi_{00}=\pi_{11}=3 / 8$ and $\pi_{01}=\pi_{10}=1 / 8{ }^{28}$ Thus the probability distribution over $\left(s_{p}, s_{d}\right)$ realizations can be represented by the matrix

$$
\Pi=\left[\begin{array}{cc}
\frac{3}{8} & \frac{1}{8} \\
\frac{1}{8} & \frac{3}{8}
\end{array}\right],
$$

\footnotetext{
${ }^{25}$ For detailed discussions of why the standard Coase result might not hold when there is private information, see, e.g., McKelvey and Page (2002), McKelvey and Page (1999), and Farrell (1987).

${ }^{26}$ That mechanism itself is based on an idea discussed in Cremer and McLean (1988).

${ }^{27}$ That requirement is not a nicety, given that a court's order that the parties participate in the type of mechanism described here might well be treated as violating one or more Federal Rules of Civil Procedure, whereas voluntary compliance might not.

${ }^{28}$ This example is adopted from Kushnir (2014).
} 
with the plaintiff's type held constant along the rows and the defendant's type held constant along the columns. ${ }^{29}$ The type distribution is dependent in this case: the marginal probability that a party has signal $s_{i}=x$ is one-half for $x \in\{0,1\}$, while the conditional probability that $s_{i}=x$ given that $s_{j}=x$ is three-fourths. Thus, types in this example are positively correlated, reflecting the likelihood that knowledge that one party believes discovery will help the plaintiff should increase the probability that the other party will think this same thing.

In an appendix available online, I construct a class of mechanisms in three steps. First, assuming that the plaintiff owns the right to insist on discovery, I introduce the incentive compatible "pre-mechanism" in McAfee and Reny (1992). This mechanism is a specialization of the dominant-strategy double auction in McAfee (1992) to the oneseller, one-buyer case, and it can be viewed as an extension of the Vickrey auction to the double-auction setting: ${ }^{30}$ (i) each party reports a value; (ii) the discovery right is allocated to whichever party's reported value is greater; (iii) the party that wins the auction pays a fee equal to the loser's reported value; and (iv) the party that loses the auction pays a fee equal to the winner's reported value. This pre-mechanism will transfer the right to avoid discovery whenever there is ex post surplus from doing so, so it is ex post efficient.

Obviously, though, the pre-mechanism requires net outside subsidies from the Court. Therefore, the second step is to construct a set of participation fees that the parties must pay if they wish to participate in the pre-mechanism designed in step one. These participation fees extract all surplus from the parties, leaving them just indifferent between participating in the auction and not doing so. Thus there is net positive revenue from the combined operation of the pre-mechanism and the participation fees.

The third step is to determine a pair of lump-sum transfers to the parties, whose total amount equals the (expected) surplus extracted via the second-step participation fees, so that the parties rather than the court realize all gains from trade. By varying the share of the surplus received by each party via these lump-sum transfers, the court can achieve any distribution of the discovery settlement surplus across the parties.

I provide details on the construction of this mechanism in the online appendix. Under the default rule that the requester-plaintiff owns the right to discovery, the mechanism following step two can be summarized by the following transfer functions $\widetilde{T}_{p}$ and $\widetilde{T}_{d}$

\footnotetext{
${ }^{29}$ It would be straightforward to rework my model so that parties' signals provide information about the probability that the fact finder would find the defendant liable, with this probability then revealed to both parties once discovery occurs. Assuming party $i$ knows the conditional distribution of party $j$ 's signal given $i$ 's observed signal, the probabilities $\pi_{s_{p} s_{d}}$ represented in the matrix $\Pi$ would be calculable for each party. All that is needed for a mechanism of the type I discuss in this section to exist is for the matrix $\Pi$ to exhibit statistical dependence; I have verified that there exists a version of such a model that generates the specific numbers used in (1). I have chosen not to present such a model since it is notationally more involved. Also, in such a model, case settlement would always happen immediately after discovery, contradicting the fact that some cases do go to trial in the real world.

${ }^{30}$ See, e.g., Yoon (2001).
} 
specifying amounts paid by the parties to the court: ${ }^{31}$

$$
\begin{aligned}
& \widetilde{T}_{p}\left(s_{p}, s_{d}\right)= \begin{cases}\frac{1}{8} c+\frac{3}{8} \alpha-\frac{11}{8} \lambda, & s_{p}=0, s_{d}=0 \\
-\frac{3}{8} c-\frac{9}{8} \alpha+\frac{1}{8} \lambda, & s_{p}=0, s_{d}=1 \\
\frac{9}{8} c+\frac{3}{8} \alpha-\frac{3}{8} \lambda, & s_{p}=1, s_{d}=0 \\
-\frac{3}{8} c-\frac{9}{8} \alpha+\frac{1}{8} \lambda, & s_{p}=1, s_{d}=1\end{cases} \\
& \widetilde{T}_{d}\left(s_{p}, s_{d}\right)= \begin{cases}\frac{5}{8} c-\frac{1}{8} \alpha+\frac{9}{8} \lambda, & s_{p}=0, s_{d}=0 \\
\frac{5}{8} c-\frac{1}{8} \alpha+\frac{9}{8} \lambda, & s_{p}=0, s_{d}=1 \\
\frac{9}{8} c+\frac{3}{8} \alpha-\frac{3}{8} \lambda, & s_{p}=1, s_{d}=0 \\
\frac{9}{8} c+\frac{11}{8} \alpha-\frac{3}{8} \lambda, & s_{p}=1, s_{d}=1\end{cases}
\end{aligned}
$$

It can be shown that party $i$ 's expected payoff, given its type $s_{i}$ and taking expectations over the conditional distribution of party $j$ 's type, equals the payoff that party $i$ would receive in the absence of any trade. Therefore this mechanism satisfies the usual interim individual rationality constraint. ${ }^{32}$ This mechanism can also be shown to raise net expected revenue in the amount of $R=\frac{7}{8} c+\frac{1}{8}(\alpha-\lambda)$, which can be redistributed to the parties in lump-sum fashion. Let $\rho$ be the share of this revenue that the court assigns to the plaintiff. Then the transfers from the parties to the court will be

$$
\begin{aligned}
T_{p}^{*}\left(s_{p}, s_{d}\right) & \equiv \widetilde{T}_{p}\left(s_{p}, s_{d}\right)-\rho R \\
T_{d}^{*}\left(s_{p}, s_{d}\right) & \equiv \widetilde{T}_{d}\left(s_{p}, s_{d}\right)-(1-\rho) R .
\end{aligned}
$$

It can be shown that the parties' expected payoffs that result from this " $\rho$-mechanism" are

$$
\begin{aligned}
& E U_{p}(\rho) \equiv \frac{1}{2}(\alpha+\lambda)+\rho R \\
& E U_{d}(\rho) \equiv-c-\frac{1}{2}(\alpha+\lambda)+(1-\rho) R .
\end{aligned}
$$

Now I compare these payoffs to the expected complete information payoffs, with the expectation taken with respect to the probability distribution $\Pi$ and using the responderpays discovery cost allocation rule. Plaintiffs in that scenario can be shown to obtain an average payoff of $\frac{1}{2}(\alpha+\lambda)+\beta R$, where we recall that $\beta$ is the share of the Coasean surplus the plaintiff would obtain via bargaining in the counterfactual complete information world. Defendants can be shown to obtain an average payoff of $-c-(\alpha+\lambda) / 2+(1-\beta) R$.

\footnotetext{
${ }^{31}$ Note that by the revelation principle, Myerson (1981), there is no loss of generality in defining these transfer functions directly in terms of the parties' signals.

${ }^{32}$ That is, it satisfies the interim individual rationality constraint governing participation decisions of an agent who knows her own type but knows only the probability distribution over the other agent's type.
} 
By setting $\rho=\beta$, the mechanism designing court can give the parties exactly the payoffs they would receive under complete information with the responder-pays discovery cost allocation rule. In fact, by varying $\rho$ all the way from 0 to 1 , the court can achieve a wide array of payoff distributions. Thus, using the augmented mechanism is like stapling together the Coase theorem and the second fundamental welfare theorem: not only does it achieve the ex post efficient allocation of resources with respect to discovery, it also achieves the functional equivalent of the distribution of welfare corresponding to any court-chosen distribution of bargaining power between the parties, given the discovery cost allocation rule.

What if we instead assume the default rule is that the responder owns the right to avoid requested discovery? Under the responder-can-refuse discovery cost allocation rule, expected payoffs would be $\frac{1}{8} \beta(\alpha-c-\lambda)$ for plaintiffs and $\frac{1}{8}(1-\beta)(\alpha-c-\lambda)$ for defendants. A class of mechanisms similar to the one constructed for the responderpays case can be shown to exist, such that the parties' expected payoffs under these mechanisms are.

In sum, if the class of mechanisms described above were feasible, they would allow the court to achieve discovery-resource allocation goals while holding the payoff distribution at its status quo, or achieving any of a wide range of possible distributions. Of course, these mechanisms require the court to have an enormous amount of information, which it is not plausible the court will have. Accordingly, I turn next to discuss the performance of several mechanisms that would be administratively feasible.

\section{Feasible Mechanisms}

Throughout this section, I drop the assumption that the court knows the particular values of any of the parameters $c, \lambda$, or $\alpha$, or the probability distribution over types. Here I consider three administratively feasible mechanisms. The first involves the holding of an auction over the right to request or refuse discovery. Second, I consider a postedprice mechanism. Third, I offer some brief observations concerning the Chatterjee and Samuelson (1983) split-the-difference mechanism.

\subsection{Auctioning Off the Right to Discovery}

One possibility is to auction off the right to demand or avoid discovery. The court could hold a second-price, sealed-bid auction. It is well known that bidding one's valuation is a weakly dominant strategy in such auctions with private values. If the parties did so, then the plaintiff would win the auction when her signal is $s_{p}=1$ and the defendant's is $s_{d}=0$. The plaintiff would then have to pay the court $c+\lambda$-the defendant's overall cost of providing the discovery - and would gain the discovery that plaintiff values at $\alpha$. In the other three states, the defendant would win the auction. In two of these, those in which $s_{p}=0$, the defendant would pay the plaintiff's bid, which is $\lambda$. In the fourth state, which happens with probability $3 / 8$, the defendant would bid $c+\alpha$ and the plaintiff would bid $\alpha$, so the defendant would pay the court $\alpha$. Before any auction revenue were redistributed to the parties, the auction would afford the plaintiff an expected payoff of 
$(1 / 8)(\alpha-c-\lambda)$; the defendant's expected payoff would be $-[(1 / 8) c+(3 / 8) \alpha+(5 / 8) \lambda]$. Notice that these payoffs are the same sign as those received by the parties under the responder-pays rule without trade. However, the magnitudes are less favorable to the plaintiff and more favorable to the defendant.

I have not yet discussed the auction's revenue. Averaged over all party-type combinations, the revenue equals $(1 / 8) c+(3 / 8) \alpha+(5 / 8) \lambda$. If this revenue could somehow be redistributed as a lump-sum transfer to the plaintiff, it would leave the plaintiff with $(\alpha+\lambda) / 2$, exactly equal to the ex ante payoff a plaintiff with no bargaining power would receive under complete information with a default rule of responder pays. Thus with distribution of all revenue to the plaintiff, the second-price auction rule is equivalent to a responder-pays system in which the plaintiff has no bargaining power, so that she captures none of the surplus from discovery settlement.

But notice that if the court does not know $\alpha, c$, and the probability distribution of types, then it would have a hard time determining how much to transfer in lump-sum fashion. That it is important because any distribution of the auction revenue must be done so as not to affect the parties' incentives, if we wish to retain the auction's incentive compatibility. If all disputes really had the simple parameters and type distribution assumed for illustration, then the court could just average over the first few trials. But since real-world conditions will have heterogeneous types and cost and discovery parameters, which the court won't know in advance, it seems unlikely that the court would be able to calibrate lump sum transfers very precisely. ${ }^{33}$

In sum, auctioning off the discovery right would avoid disfavored discovery and provide discovery when it is privately subjectively efficient to do so. It would also raise revenue via the auction, which could be redistributed to the parties, though under the informational assumptions of this section, it would be difficult for the court to know how to do so. Finally, in the absence of any redistribution of auction revenue, and even likely with such redistribution, an auction approach would redistribute ex ante payoffs from plaintiffs to defendants relative to the status quo rule.

\subsection{Posted Prices}

As footnote 10 explains, a proposed amendment to Rule 26(c) would allow the court to allocate some or all of the costs of discovery to the requester. Suppose the court orders that the responder must provide the requested discovery, but only if the requester reimburses the responder by some stated amount $p$. This is an example of a posted-price mechanism with the discovery right initially assigned to the requester. In general, given a discovery cost allocation rule, a court using the posted-price approach would announce a price, $p$, and the discovery right would be transferred from the default holder to the other party if and only if both parties agreed to transact at that price.

An attractive feature of the posted-price mechanism is its administrative simplicity.

${ }^{33}$ The existence of a surplus is a standard result with the use of Vickrey-Clarke-Groves mechanisms, of which the second-price, sealed-bid auction is an example. What to do with the surplus is a well known problem. 
In addition, it is dominant-strategy incentive compatible, ${ }^{34}$ so we can again work with the parties' actual valuations. Unfortunately, the mechanism is not ex post efficient except by luck. To illustrate, suppose the requester owns the discovery right. Suppose the court doesn't know the value of $\lambda, \alpha, c$, or any linear combination of these parameters. If the court chooses $p<\lambda$, then the plaintiff-requester will not agree to trade when $s_{p}=0$, and there will be no trade, even though the responder would be willing to pay more than $\lambda$. Thus it is inefficient for discovery to occur when $s_{p}=0$, but with a poorly chosen price, the posted-price mechanism will yield that result. For another example, suppose the responder-can-refuse rule is in place. If the court chooses $p<c+\lambda$, then the responder will not agree to sell when $s_{d}=0$, even though the requester would be willing to pay more than $c+\lambda$. With a low enough posted price, then, discovery does not occur even when it would be subjectively efficient.

In both cases, the parties will truthfully reveal whether they would be willing to transact at the posted price, but that won't matter since the court errs by posting a price below the reservation value of the discovery right's default owner. Thus, the risk of the posted-price approach is that too little trade will occur if the court lacks the information necessary to make a good price choice.

\subsection{Splitting the Difference}

A final administratively feasible mechanism is the Chatterjee-Samuelson ("CS") split the difference mechanism. With this mechanism, the parties each report prices. If the reported price for the owner of the discovery right exceeds the reported price for the other party, then no transfer of the discovery right occurs. If instead the discovery right owner reports the lower price, then the discovery right is transferred at the average of the two reported prices. Truthtelling is not a weakly dominant strategy with this mechanism. Conditional on the occurrence of a transfer, each party would do better if it moved its reported price in the direction of the other party's report. Thus the parties have incentives to bid strategically. Consequently, trade will sometimes fail to occur when it would be efficient as with the posted-price mechanism.

\section{The Role of Pre-Discovery Settlement}

As noted above, joint stipulations aside, we do not generally hear about discovery settlements - in other words, we do not hear about agreements in which one side pays the other money in return for a unilateral stipulation not to pursue discovery as to a matter.

One reason why not is an inference related to adverse selection, one that is essentially assumed away in the model above. If a defendant offered a plaintiff a large amount of money to forego discovery on a particular matter, a reasonable plaintiff might well assume that the defendant must know the discovery will yield evidence with a high

\footnotetext{
${ }^{34}$ See Yamashita (2015), who also discusses certain robust optimality properties that postedprice mechanisms have.
} 
value to the plaintiff. Thus, the plaintiff would update her beliefs concerning the value of discovery and reject the offer; she might even demand more discovery than she otherwise would have. Of course, it is possible that the defendant simply has a high cost of providing discovery. In many cases the defendant should be able to credibly demonstrate that her discovery costs are high (the proportionality standard certainly seems predicated on this idea), so the adverse selection explanation may not be universally relevant.

Whatever the reason that we do not see discovery settlements, we certainly do often see overall case settlements in the period before major discovery occurs. A natural question is whether overall settlements are functionally equivalent to discovery settlements. Assume the responder pays discovery cost allocation rule is in place, and assume that discovery settlements never happen. The following table reports the overall payoffs of each player given each pair of signal values, together with the surplus:

\begin{tabular}{ccccl}
\hline & \multicolumn{4}{c}{ Payoffs } \\
\cline { 2 - 4 }$\left(s_{p}, s_{d}\right)$ & Plaintiff & Defendant & Surplus & Settle pre-discovery? \\
\hline$(0,0)$ & $q-\tau+\lambda$ & $-(\tau+c+\lambda)$ & $2 \tau-q+c$ & If and only if $c>q-2 \tau$. \\
$(0,1)$ & $q-\tau+\lambda$ & $-(\tau+c+\alpha)$ & $2 \tau-q+c+\alpha-\lambda$ & If and only if $c+(\alpha-\lambda)>q-2 \tau$. \\
$(1,0)$ & $q-\tau+\alpha$ & $-(\tau+c+\lambda)$ & $2 \tau-q-[\alpha-c-\lambda]$ & No. \\
$(1,1)$ & $q-\tau+\alpha$ & $-(\tau+c+\alpha)$ & $2 \tau-q+c$ & If and only if $c>q-2 \tau$. \\
\hline
\end{tabular}

It is useful to compare the surplus in each of the four signal states to the surplus in the event of trial with only common knowledge evidence. We saw in section 2 that this latter surplus is $2 \tau-q$, which is negative. In the $(1,0)$ state, the fact that discovery is subjectively efficient causes overall surplus to become even more negative: the possibility of discovery in this realized signal state makes overall settlement even less of a good idea, subjectively, than it would be if only common knowledge evidence were available.

However, in all three other states, the possibility of discovery increases the surplus from settlement. This is true because in each of these states, conducting discovery is worth subjectively less to the plaintiff than avoiding it is worth to the defendant. If the defendant's cost of conducting discovery is large enough - if $c>q-2 \tau$ - then there will be positive surplus from overall case settlement due to the possibility of discovery. Further, even if discovery doesn't cost that much, it is possible that surplus is positive in the $\left(s_{p}, s_{d}\right)=(0,1)$ state, since in that state we require only $c+\alpha-\lambda>q-2 \tau$, and we assumed that $\alpha>\lambda$. In fact, the condition $c>q-2 \tau \equiv c^{*}$ is sufficient for there to be positive settlement surplus in three of the four states - seven-eighths of the time. When $c>c^{*}$, there will be positive pre-discovery settlement surplus if and only if discovery settlements would be efficient. Of course, with private information about ex ante discovery-related beliefs, there is no guarantee that pre-discovery settlement will occur just because surplus is available. Still, this discussion shows that even when efficient discovery settlements aren't feasible for some reason, there is at least the possibility that discovery costs (and, sometimes, differences in party assessments of discovery results) will grease the wheels of overall settlement.

Two further points warrant discussion here. First, it is well understood that high discovery costs might be the cause of pre-discovery settlements. This observation is typ- 
ically made ominously. For example, in his memorandum forwarding the proposed Rule 26 amendments, Advisory Committee Chair Judge David G. Campbell characterized public commenters who favored the proposal as "assert[ing] that costs of discovery in civil litigation are too often out of proportion to the issues at stake in the litigation, resulting in ... settlements made to avoid litigation costs regardless of the merits." 35 And the Supreme Court has made the point, too, emphasizing

the potential for possible abuse of the liberal discovery provisions of the Federal Rules of Civil Procedure ... [via, among other things,] extensive discovery of business documents.... To the extent that this process eventually produces relevant evidence which is useful in determining the merits of the claims asserted by the parties, it bears the imprimatur of those Rules and of the many cases liberally interpreting them. But to the extent that it permits a plaintiff with a largely groundless claim to simply take up the time of a number of other people, with the right to do so representing an in terrorem increment of the settlement value, rather than a reasonably founded hope that the process will reveal relevant evidence, it is a social cost rather than a benefit. Blue Chip Stamps v. Manor Drug Stores, 421 US 723, 741 (1975).

In the context of my little model, we might think of the Blue Chip Stamps Court as expressing concern over the possibility that settlement will be enabled when the $s_{p}=s_{d}=0$ signal state is realized. In this situation, both parties expect discovery to yield little of use to the plaintiff, but settlement might occur, and on decent terms for the plaintiff, if the cost of discovery, $c$, is large enough. The flipside of such a concern is that in the signal state $s_{p}=s_{d}=1$, both parties think discovery will yield highly valuable evidence, settlement surplus is the same as in the $s_{p}=s_{d}=0$ case. Presumably, the Blue Chip Stamps Court would endorse a settlement made possible by high discovery costs in that situation; certainly the Marek v. Chesny Court should, given its endorsement of a federal policy of encouraging settlement of "all lawsuits."

Thus, the same high discovery costs that inappropriately enable settlement and "in terrorem" increments to settlement amounts also enable discovery-avoiding settlements that courts tend to view as beneficial. This discussion points to the possibility that there may be a need for federal courts to make trade offs among policy goals that cannot all be achieved: it is not clear that it will be possible simultaneously to (i) encourage settlement of plausibly meritorious suits, (ii) avoid the use of discovery costs as a lever to increase settlement value when discovery is likely to have low value to the plaintiff, and (iii) avoid major departures from the default rule that responders bear the costs of discovery. Policy discussions related to proportionality in discovery have not generally recognized this tension.

The second point is that if the reason the parties can't efficiently forge discovery settlements has to do with informational bargaining problems, then we shouldn't be too quick to assume that pre-discovery overall settlements will occur simply because

\footnotetext{
${ }^{35}$ See Hon. David G. Campbell, Memorandum to Hon. Jeffrey Sutton, June 14, 2014, page 5.
} 
settlement surplus is positive. The parties surely can be expected to price their expectations related to discovery into pre-discovery overall settlements. Bargaining problems with discovery settlements might thus be expected to migrate into the pre-discovery stage. The assumption that parties always realize positive settlement surplus is surely more tenuous in this situation than when only common knowledge evidence is involved. Further analysis of this issue is beyond the scope of the present paper.

\section{Conclusion}

This paper has discussed a number of issues related to changes likely to take effect, later this year, in the rules governing discovery in U.S. civil litigation. Added emphasis on the "proportionality" of discovery may require trial courts to determine when and on what terms certain discovery requests - presumably, relatively expensive ones whose value to the requester is disputed - will be allowed. My focus in this paper has been on the extent to which judicial involvment in such disputes is really necessary, on the allocative and distributional effects of changing the default rule that responders pay, and on administratively feasible mechanisms judges might consider using when they must get involved.

One result of the paper's highly stylized model is that if the court has enough information to implement anything like a real cost-benefit test concerning disputed discovery, then - for dependently distributed types - it would also have enough information to implement a kind of Nirvana mechanism. This mechanism is incentive compatible, interim individually rational, and ex post efficient, it has a balanced budget, and it allows the court to pick among a wide range of distributional consequences. Essentially, the mechanism allows the court to reproduce what would happen if the parties had complete information and could bargain costlessly.

In reality, the court is unlikely to have such detailed information. Thus, it will have to resort to administratively feasible mechanisms for adjudicating discovery proportionality disputes. I discuss three such mechanisms. A second-price auction of the discovery right induces truth-telling and efficient allocation of discovery resources but entails a substantial, and surely controversial, redistribution away from plaintiffs relative to the default discovery cost allocation rule. A posted-price mechanism avoids such distributional effects, but if the court is unlucky in its price choice, discovery can be either underor over-used (depending on the default rule over discovery rights). A split-the-difference mechanism may induce strategic behavior that also leads to inefficiencies.

In sum, all of the administratively feasible mechanisms considered have some important drawback. And which drawback is worse generally will depend on the very parameters the court is assumed not to know. I conclude that while mechanism design could do great things for a court with great information, it may be of limited help for one with limited information. 


\section{References}

Burbank, S. B. (2015), "Proportionality and the Social Benefits of Discovery: Out of Sight and Out of Mind?" Review of Litigation, 34.

Chatterjee, K., and W. Samuelson (1983), "Bargaining under Incomplete Information," Operations Research, 31(5), 835-51.

Cooter, R. D., and D. L. Rubinfeld (1994), "An Economic Model of Legal Discovery," Journal of Legal Studies, 435-63.

Cremer, J., and R. P. McLean (1988), "Full Extraction of the Surplus in Bayesian and Dominant Strategy Auctions," Econometrica, 56(6), 1247-57.

Daughety, A., and J. F. Reinganum (2012), "Settlement," in: C. W. Sanchirico (ed.), The Encyclopedia of Law and Economics, vol. 8, Edward Elgar Publishing, LTD.

Daughety, A. F., and J. F. Reinganum (1993), "Endogenous Sequencing in Models of Settlement and Litigation," Journal of Law, Economics and Organization, 9, 314-XX.

Daughety, A. F., and J. F. Reinganum (2014), "Revelation and Suppression of Private Information in Settlement-Bargaining Models," University of Chicago Law Review, 81(1), 83-108.

Donohue, J. J. (1991), "Opting for the British Rule: Or, If Posner and Shavell Can't Remember the Coase Theorem, Who Will?" Harvard Law Review, 104, 1093-11XX.

Farmer, A., and P. Pecorino (2013), "Discovery and Disclosure with Asymmetric Information and Endogenous Expenditure at Trial," Journal of Legal Studies, 42(1), 223-47.

Farrell, J. (1987), "Information and the Coase Theorem," Journal of Economic Perspectives, $1(2), 113-29$.

Gelbach, J. B. (2015), "Discovering Coase," Tech. rep., University of Pennsylvania Law School, draft prepared for the first annual Civil Procedure Workshop at Seattle University.

Gelbach, J. B., and B. H. Kobayashi (forthcoming), "The Law and Economics of Proportionality in Discovery," Georgia Law Review, 50.

Hay, B. L. (1994), "Civil Discovery: Its Effects and Optimal Scope," Journal of Legal Studies, 23, 481-515.

Kaplow, L. (1994), "The Value of Accuracy in Adjudication: An Economic Analysis," The Journal of Legal Studies, 23(1), 307-401.

Kushnir, A. (2014), "On the Equivalence of Bayesian and Dominant Strategy Implementation: The Case of Correlated Types," Accessed on May 21, 2015, from http://www.andrew.cmu.edu/user/akushnir/.

Lee, Y., and D. M. Klerman (2014), "The Priest-Klein Hypotheses: Proofs, Generality and Extensions," Tech. rep., USC CLASS Research Paper No. 14-34, available at http://dx.doi.org/10.2139/ssrn.2538854.

McAfee, P. (1992), "A dominant strategy double auction," Journal of Economic Theory, 56, $434-50$.

McAfee, R. P., and P. J. Reny (1992), "Correlated Information and Mechanism Design," Econometrica, 60, 395-421.

McKelvey, R. D., and T. Page (1999), "Taking the Coase Theorem Seriously," Economics and Philosophy, 15(2), 235-47.

McKelvey, R. D., and T. Page (2002), "Status Quo Bias in Bargaining: An Extension of the MyersonSatterthwaite Theorem with an Application to the Coase Theorem," Journal of Economic Theory, 107(2), 336 - 355, doi:http://dx.doi.org/10.1006/jeth.2001.2954, URL http://www.sciencedirect.com/science/article/pii/S0022053101929540. 
Mnookin, R. H., and R. Wilson (1998), "A Model of efficient discovery," Games and Economic Behavior, 25, 219-50.

Mullenix, L. S. (1994), "Discovery in Disarray: The Pervasive Myth of Pervasive Discovery Abuse and the Consequences for Unfounded Rulemaking," Stanford Law Review, 46(6), $1393-45$.

Myerson, R. B. (1981), "Optimal Auction Design," Mathematics of Operations Research, 6(1), $58-73$.

Myerson, R. B., and M. A. Satterthwaite (1983), "Efficient Mechanisms for Bilateral Trading," Journal of Economic Theory, 29, 265-81.

Redish, M. H. (2012), "Pleading, Discovery, and the Federal Rules: Exploring the Foundations of Modern Procedure," Fla. L. Rev., 64, 845-.

Rosenberg, D., and K. E. Spier (forthcoming), "Incentives to Invest in Litigation and the Superiority of the Class Action," Journal of Legal Analysis, september 12, 2014 version accessed at http://ssrn.com/abstract=1950196.

Schweizer, U. (1989), "Litigation and Settlement under Two-Sided Incomplete Information," Review of Economic Studies, 56, 163-77.

Shavell, S. (1982), "Suit, Settlement, and Trial: A Theoretical Analysis under Alternative Methods for the Allocation of Legal Costs," Journal of Legal Studies, 11(1), 55-81.

Shavell, S. (1989), "The sharing of information prior to settlement or litigation," 20, 183-95.

Shavell, S. (1997), "The Fundamental Divergence between the Private and the Social Motive to Use the Legal System," Journal of Legal Studies, 26.

Sobel, J. (1989), "An Analysis of Discovery Rules," Law and Contemporary Problems, 52, 133-XX.

Wickelgren, A. L. (2013), "Law and Economics of Settlement," in: J. Arlen (ed.), Research Handbook on the Economics of Tort Law, Edward Elgar Publishers.

Yamashita, T. (2015), "Implementation in Weakly Undominated Strategies: Optimality of Second-Price Auction and Posted-Price Mechanism," Review of Economic Studies, URL http://www.restud.com/wp-content/uploads/2015/01/MDwithRationalAgents-03-09.pdf.

Yoon, K. (2001), "The Modified Vickrey Double Auction," Journal of Economic Theory, 101, $572-84$.

Jonah B. Gelbach

University of Pennsylvania Law School

University of Pennsylvania

3501 Sansom Street

Philadelphia, PA 19104

U.S.A.

jgelbach@law.upenn.edu 